\title{
Futuros que Seguem: Multiplicidade Espaçotemporal Businenge no Suriname Pós-Colonial
}

\author{
Rogério Brittes W. Pires \\ Universidade Federal de Minas Gerais, Belo Horizonte, Brasil \\ E-mail: rogeriobwp@gmail.com
}




\section{Resumo}

Conecto uma questão derivada da etnografia businenge a conceitos acerca da pós-colônia. Na língua saamaka, as principais catacreses que pareiam espaço e tempo colocam o futuro atrás e o passado na frente, porém, ao se referirem ao progresso, as figuras que utilizam são invertidas. Analiso tal duplicidade pensando o emaranhamento de temporalidades da época pós-colonial e a ideia de tradição como terreno de dissonância política e de construção ativa de relações entre passados e futuros.

Palavras-chave: Businenge. Suriname. Espaço-Tempo. Tradição. Pós-Colônia.

\section{Abstract}

I connect a problem stemming from Maroon ethnography to concepts about the postcolony. In the Saamaka language, the main catachresis connecting time and space place the future behind and the past ahead, but when Saamaka people talk about progress such figures are inverted. My analysis of this duplicity tackles the entanglement of temporalities in the postcolonial age, and the idea of tradition as a contentious political arena where the relationship between pasts and futures are constructed.

Keywords: Businenge. Suriname. Space-Time. Tradition. Postcolony. 


\title{
1 O Suriname e os Businenge diante da Categoria Teórica, Política e Espaçotemporal "Pós-Colônia"1
}

\author{
And if the idea of the New and the Old becomes increasingly absurd, \\ what must happen to our sense of time, what else can happen to \\ history itself, but that it, too, is becoming absurd? \\ (Derek Walcott, The Muse of History) \\ Comme le Même a commencé par la rapine expansionniste en \\ Occident, le Divers s'est fait jour à travers la violence politique et \\ armée des peuples. \\ (Édouard Glissant, Le Discours Antillais)
}

s historiadores neerlandeses Gert Oostindie e Inge Klinkers (2003,
p. 9) iniciam seu volume comparativo acerca da descolonização do Caribe afirmando que as guerras e os tratados de paz com os businenge do Suriname ${ }^{2}$ e com os maroons da Jamaica ${ }^{3}$ ao longo dos séculos XVII e XVIII não tiverem efeitos na história que contam - uma história centrada nas independências nacionais, que teria efetivamente começado com a revolução haitiana, em 1791. O ponto é marginal para o argumento dos autores: é somente um modo de iniciar sua obra sem ignorar totalmente as comunidades de escravos fugitivos, mas sem se preocupar em encontrar sua relevância na história da região e do mundo. Mas cabe questionar a deliberada exclusão. Sabe-se que informações acerca dos tratados de paz entre os maroons jamaicanos e a coroa britânica chegaram aos ouvidos de Toussaint de L'Ouverture (James, 2000, p. 205). Ademais, o papel dos nègres marrons/ neg'mawons haitianos na primeira revolução caribenha há muito é sublinhado e discutido (Carvalho, 1996, p. 23-31). As variadas formas de lutas contra a escravidão e o colonialismo através das Américas 
certamente tiveram papel decisivo nos processos de descolonização. Ainda que não tenham sido unificadas - para tentativas explícitas de convergência teríamos de aguardar pelo pan-africanismo e pela négritude -, evidentemente tiveram influências umas sobre as outras. Seria um erro considerar qualquer forma de resistência isoladamente, de maneira que quilombismos ou marronagens, em suas variadas formas, não devem ser tomados como notas de rodapé da história.

As guerras e tratados de paz maroons e businenge deveriam ser tratados como relevantes para uma história da descolonização caribenha. E, se o ponto é marginal ao argumento de Oostindie e Klinkers, levanto-o por parecer-me fundamental questionar a posição de excepcionalidade na qual os businenge das Guianas tendem a ser encaixados nos campo dos estudos caribenhos e afro-americanos ${ }^{4}$. David Scott, em artigo publicado neste volume (Scott, [no prelo]) aponta para o fato de que os businenge (e os saamaka em particular) ocupam uma posição de iconicidade no discurso dos estudos afro-americanos (e da antropologia em particular): por sua história de fugas "precoces" das plantations e de suposto isolamento na selva amazônica, parecem exemplos perfeitos a partir dos quais sustentar argumentos acerca da relação entre o passado e o presente de populações de ascendência africana nas Américas. Sendo um caso "extremo" de comunidade fundada principalmente por pessoas que passaram por uma experiência de escravidão relativamente curta e aldearam-se nas matas, os saamaka ajudariam antropólogos (os casais Herskovits e Price em particular) a argumentarem sobre em que medida retenções africanas ou memórias da escravidão teriam peso na configuração atual das comunidades afro-americanas. Os saamaka seriam quase um tipo ideal.

No entanto, o suposto isolamento faz com que, quando o problema é outro - que não as continuidades e descontinuidades entre o presente e um passado de África e/ou de escravidão -, esses povos pareçam ser considerados pouco relevantes. Para pensar a descolonização do Caribe e das Guianas, por exemplo. A fortiori, questões ditas "póscoloniais" parecem irrelevantes para a literatura que trata desses povos. Ocorre uma curiosa inversão: por um lado, os businenge concentram desproporcional atenção dos antropólogos e historiadores 
que trabalham no/com o Suriname, em detrimento dos creole e dos surinameses de ascendência asiática; por outro, o interesse neles parece esmaecer quando o assunto passa pela diáspora caribenha na Europa, relações internacionais pós-independência, identidades nacionais ou governamentalidade pós-colonial.

Muitos fatores podem explicar tal dupla irrelevância - dos estudos businenge para os estudos pós-coloniais e dos estudos pós-coloniais para os estudos businenge. Um primeiro, vinculado à tradição herskovitsiana, é que esses povos foram amiúde vistos como representantes de uma tradição africana quase pura nas Américas, com grau mínimo de aculturação, representando uma espécie de imagem da África précolonial transplantada para o Novo Mundo (Herskovits, 1929; 1941). Uma versão talvez mais fraca dessa visão coloca os businenge como povos tribais (aldeados, divididos em clãs etc.) e, portanto, mais aptos a dialogarem com uma teoria antropológica "clássica", que tende a mitigar a importância das relações entre as comunidades estudadas e "influências externas" - estados, mercados, colonialismos. Tais posicionamentos, obviamente problemáticos, não são dominantes na bibliografia que trata destes povos, que se ocupou, ao menos desde os anos 1980, da relação dos mesmos com os estados e mercados que os circundam (Bilby, 1990; Pakosie, 1996; R. Price, 2011; Cunha, [no prelo]). Entretanto, tais posicionamentos - nem sempre articulados, mas sugeridos por um continuado silêncio - podem explicar as atitudes dos não especialistas perante os businenge - talvez pareçam casos excepcionais demais, estranhos demais, para se levar em conta em uma discussão da contemporaneidade caribenha e pós-colonial em geral.

Outro fator a ser considerado é a resistência, por parte do establishment acadêmico das ex-metrópoles (os Países Baixos, sobretudo), a estabelecer uma discussão pós-colonial (Oostindie, 2010; Bosma, 2012; Boehmer e de Mul, 2014), aAinda que os ventos possam estar mudando, que o silêncio acerca do legado colonial neerlandês não seja simples ou absoluto (Balkenhol, 2016). Ademais, há importantes exceções, sobretudo autores de inspiração anti ou póscolonial surinameses e neerlandeses-surinameses, que mereceriam um espaço de que não disponho para serem tratados devidamente (de 
Kom, 1981; Essed, 1991; Ramdas, 1998; Wekker, 2016). Outro fator possível é de ordem sociológica e demográfica: os businenge são menos numerosos do que os creole e os indo-surinameses nos Países Baixos: ao que tudo indica não chegam a 20 mil entre cerca de 450 mil pessoas de origem surinamesa que se estima que vivam hoje na ex-metrópole (Price, 2013; Deogratias; Singleton; Wojtalewicz, 2011). Por ocuparem uma posição mais baixa na hierarquia etnorracial na ex-colônia, de maneira geral têm menos acesso a posições políticas, acadêmicas e midiáticas. Talvez os estudos e políticas de inclinação pós-colonial neerlandófonos estejam interessados nos problemas políticos e teóricos pós-coloniais na medida em que a imigração de caribenhos, africanos e asiáticos obriga a ex-metrópole a se haver com as questões de seu próprio racismo e história colonial. Assim, é possível que a clivagem interna à população afro-surinamesa, entre businenge e creole, faça pouca diferença no atual estado da discussão.

A categoria "pós-colonial", é importante marcar, possui mais de uma acepção. Uma primeira, mais descritiva, aponta para um momento histórico vivido por ex-colônias e ex-metrópoles, quando o vínculo entre elas desfaz-se ou transforma-se profundamente, a partir da independência (como no caso do Suriname, que torna-se uma república independente em 1975, após um processo de iniciado nos anos 1950) ou da mudança de status legal (como no caso da Guiana Francesa, tornada departamento ultramarino em 1947, processo aprofundado pela descentralização nos anos 1980). Pós-colonialidade, nesse primeiro sentido, é a situação política, econômica e demográfica atravessada por territórios e populações que passaram por trajetórias de descolonização, seja no papel de metrópole ou no de colônia, o que inclui processos neocoloniais.

Uma segunda acepção do termo pós-colônia aponta para uma abordagem teórico-crítica com firmes raízes nos pensadores políticos da era anticolonial (como Césaire, Fanon, de Kom, Rodney, para ficar apenas com exemplos caribenhos). A partir do final dos anos de 1970, novas reflexões ganham espaço crescente no mundo acadêmico, tendo como importantes marcos a obra de Saïd, de modo geral, e de Asad, para a antropologia. Tal abordagem se fragmenta em diversas tradições 
regionais, que se articulam de maneiras complexas: estudos culturais afro-britânicos (Hall, Gilroy, etc.); estudos subalternos sul-asiáticos (Spivak, Chakrabarty, etc.); giro decolonial latino-americano (Mignolo, Restrepo, etc); além de autores africanos (dentre os quais Mafeje e Mudimbe) e caribenhos (como Brathwaite e Wynter). Tampouco será possível dar atenção a esta complexa história intelectual. O importante é perceber que, nessa segundo acepção, os estudos pós-coloniais apontam para um tratamento do colonialismo como mais do que uma estrutura de violência e exploração material, mas também uma estrutura de conhecimento autorizado que produz efeitos de longa duração sobre os povos colonizados (Scott, 1999, p. 12). A pós-colonialidade, qual tratada pelos autores que seguem tal tendência, pode ser entendida como um emaranhado de poder-saber que atravessa os sujeitos da neo/ex-colônia, através de governamentalidades e mecanismos de subordinação que eliciam formas particulares de estar no mundo 5 .

Certamente, nem a academia neerlandesa, nem os pensadores surinameses, nem os etnógrafos dos businenge têm qualquer obrigação de aprofundarem-se nos temas e teorias apresentados pelo (anti-)cânone dos estudos pós-coloniais. Meu ponto ao questionar a dupla irrelevância deve-se menos à posição dos businenge (e de seus estudiosos, eu incluso) perante os estudos pós-coloniais, e mais à posição dos businenge (Scott, 1999) perante a pós-colonialidade enquanto momento. Suponho - e o artigo que segue é um experimento traçado a partir desta suposição - que os estudos pós-coloniais tragam reflexões interessantes para compreender os passados, presentes e futuros businenge. Tratarei "póscolônia" como uma categoria múltipla, complexa: teórica, política e espaçotemporal. Trata-se de uma época, no sentido dado à expressão por Achille Mbembe (2001a, p. 14):

[...] não uma simples categoria de tempo, mas uma quantidade de relações e configurações de eventos, muitas vezes visíveis e perceptíveis, outras vezes difusos e "policéfalos", mas que podem ser testemunhadas por contemporâneos, que têm bastante consciência dela ${ }^{6}$.

Dito em outras palavras: os businenge não costumam ser lidos como inseridos numa situação pós-colonial. Porém, se o Suriname e 
a Guiana Francesa vivem uma situação pós-colonial, e os businenge habitam esses territórios, tendo vínculos inextrincáveis com os estados nacionais que os definem (bem como com suas antigas metrópoles), faz algum sentido dar atenção a conceitos desenvolvidos por autores que tratam da situação pós-colonial, a ver se ajudam a pensar questões levantadas por etnografias realizadas entre os businenge. Eis o objetivo do presente texto: experimentar conceitos e ideias cunhados por alguns autores - em geral rotulados (de bom grado ou não) de "pós-coloniais", escolhidos por mera predileção pessoal - num contexto etnográfico onde não costumam ser acionados. A questão etnográfica central da qual tratarei diz respeito às figuras espaçotemporais utilizadas na língua saamaka (saamakatongo) e de sua aparente "inversão"7.

\section{Espaço e Tempo em Saamakatongo}

Todas as línguas conhecidas se valem de termos espaciais para falar do tempo. A fusão discursiva entre tempo e espaço é tão recorrente que, por si só nos levaria a questionar em que medida tempo e espaço podem ser efetivamente separados. Ao pensar nessas formas de expressão, encontra-se diante de catacreses - modos de expressão tão padronizados, tão sedimentados que tendem a não serem sentidos como figurados, não são pensados como figuras de linguagem. De fato, a catacrese se coloca no limite entre a dimensão contígua e cotidiana da metonímia e a dimensão analógica e poética da metáfora (Laclau, 2007). Na maioria das línguas, tais catacreses pareiam o futuro com "frente" e o passado com "trás". Dizer, como fazemos em português, que o passado é "aquilo que já passou", "o que ficou pra trás" e que o futuro é "o que chegará", o que "está diante de nós" é forma mais comum de falar do tempo nas línguas indo-europeias.

Serão evitados argumentos generalistas sobre a relação entre tempo e espaço. Mas, no Alto Suriname, que é o que mais nos interessa, toda história é narrada com relação a genealogias e localidades. Os ancestrais são marcados por sua relação com sua prole (e, portanto, com clãs e matrilinhagens) e ao mesmo tempo pelos locais onde viveram, tiveram roças, encontros com espíritos, conflitos, ou morreram. Junto com fragmentos genealógicos, a toponímia é uma das principais fontes 
de conhecimento histórico: o ancoradouro da aldeia Botopasi é chamado de kabiteni pasi (lit. "caminho do capitão") porque o capitão Janie, pai de Siemetie, aportava ali sua canoa, no passado; a antiga aldeia Sofibuka (lit. "boca de Sofi") tem esse nome porque foi construída na boca do igarapé onde Sofi, mãe de Sialoto e sogra de Alabi, foi enterrada. Inversamente, os mapas mentais do território saamaka, sua forma de navegação espacial, são todos marcados por eventos, antigos e recentes: para chegar a determinado local onde é bom caçar bugio, é preciso seguir uma trilha até onde tal pessoa tinha uma roça, entrar na mata de helicônias até o pé de inajá que outro homem gostava de colher, atravessar um igarapé que carrega o nome de um ancestral. O espaço é tempo, em saamaka, sua história é movimento.

Partindo de tal imbricação catacréstica do espaço-tempo em sua expressão discursiva, o que torna as línguas businenge peculiares é que, em grande parte de suas expressões comuns, os exemplos indoeuropeus que vimos acima são "invertidos"8: o futuro se encontra

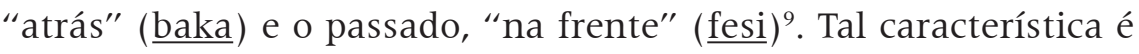
compartilhada com poucas outras línguas pelo mundo - as de que tenho notícia são o aymara (Núñez; Sweetser, 2006) e o fijiano (Toren, 2010, p. 25). Tratarei dessa questão a partir de dados que coletei entre os Saamaka, mas um padrão idêntico foi notado para as línguas ndyuka, pamaka e aluku (Goury; Migge, 2003, p. 133).

Em saamakatongo, o passado é "fesiten" (literalmente "os tempos da frente") e o futuro, "bakaten" (lit. "os tempos de trás"). Porém, este primeiro nível diz ainda muito pouco. Quase nada informam sobre as concepções de espaço e tempo saamaka expressões como "baka jai liba" ("fevereiro", lit. "mês depois/atrás do ano novo"), "wo miti baka" ("nos encontraremos de novo/atrás") ou " $\underline{\text { fesi u njan" ("antes/na frente }}$ de comer"). Neste nível mais abstrato, é difícil propor qualquer tipo de conexão entre língua, história e visão de mundo. Há, entretanto, figuras de segundo nível que, ao menos para falantes não nativos, apontam para um uso mais metafórico. Um descendente é chamado de "bakamii" ("criança de trás") e, inversamente, ancestrais podem ser referidos coletivamente como "de sembe di waka a fesi" (lit. "as pessoas que andaram na frente"). Participei, em Botopasi, de uma reunião-geral na qual se discutia a implementação de mudanças na 
maneira como eram celebrados os ritos funerários. Como argumento contra as novidades, um homem disse a frase "a gaansembe baka u ta waka aki" ("aqui andamos atrás dos velhos"), ou seja, faz-se as coisas à maneira dos anciões, dos antigos, dos antepassados - à maneira tradicional, digamos.

Tais usos sugerem um conjunto particular de catacreses espaçotemporais. Numa imagem espaçotemporal recorrente nas línguas indo-europeias, é o tempo que se movimenta, e a perspectiva necessariamente presentista do falante acompanha seu deslocamento. Assim, podemos pensar que alguém pode estar "vendo as horas passarem", "correndo atrás do tempo perdido", ou mesmo excepcionalmente "à frente de seu tempo". A imagem-chave em saamakatongo parece ser outra: buscando referências na genealogia e na história, o tempo pode ser pensado como um deslocamento por uma trilha aberta no mato quem anda na frente primeiro abre caminho para que os de trás possam passar depois. Isso reflete o evento histórico fundador dos saamaka enquanto povo: a fuga das plantations para seu território tradicional, a floresta em torno do Alto Suriname. Os grandes ancestrais vieram na frente, desbravaram a floresta surinamesa para fugir da escravidão e seus descendentes (as "crianças de trás") os seguiram.

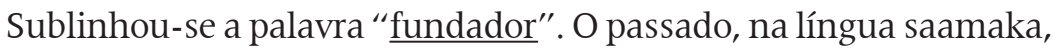
além de ser chamado de fesiten ("tempos da frente"), pode ser também referido como fosuten ("primeiros tempos"). O sinônimo marca um importante traço da concepção saamaka do tempo: a importância dos atos e eventos inaugurais, em diversas esferas. Após uma morte e um enterro de um membro da família, os parentes mais próximos do morto necessitam fazer uma cerimônia chamada puu tjina ("remover tabus"), na qual rapidamente trabalham, comem, cozinham e bebem sinedoquicamente pela primeira vez após o período mais perigoso das exéquias. Isso é feito a fim de "abrir caminhos" ("jabi pasi") para que possam voltar a viver normalmente. De maneira similar, o primeiro ato sexual de um viúvo ou viúva, ritualizado, marca o fim do período de luto. A primeira vez que se faz algo - a primeira desde sempre, ou após um evento marcante, como uma morte ou um novo ano - é um marcador temporal fundamental em saamaka. O antes e o depois de uma atividade devem ser marcados com precisão. 
Nesse sentido, merece destaque a relação com os ancestrais mais antigos guardados nas genealogias: as primeiras gerações de fugitivos do cativeiro, que inauguram clãs e matrilinhagens saamaka. Acerca desses "primeiros tempos" dos ancestrais, tão bem explorados por Price (2002), as narrativas saamaka são extremamente detalhadas ${ }^{10}$. Primeiras vezes, inícios ou recomeços, são fundamentais: ganham importância aqueles ancestrais que primeiro desbravaram uma área de mato ou rio; que primeiro cortaram uma roça num determinado lugar; que primeiro foram batizados cristãos; que primeiro entraram em contato com um determinado espírito; que primeiro aplicaram uma receita particular de obia ("magias"); que primeiro trouxeram certo alimento para as aldeias; ou que participaram da fundação de aldeias ou linhagens. Pioneiros terão destaque nas lembranças, nas rezas, nas libações, nas histórias relacionadas a um determinado local, grupo ou atividade. Essa relação com as "primeiras vezes" também determina reivindicações por território: o trabalho sobre a terra, e especialmente o trabalho inaugural, a humanização de uma área de floresta, é o que primeiro garante os direitos sobre ela - mesmo a possibilidade de transmissões posteriores não retira dos pioneiros certas prerrogativas sobre um espaço. Assim, saber detalhes sobre a qual clã pertence um território é campo de disputa entre especialistas de uma geografia histórica cercada de conhecimentos esotéricos, segredos e perigos.

Esses temas são mais complexos do que poderia aqui apresentar. O importante, no momento, é compreender que a concepção saamaka de história é, sobretudo, linear e marcada por eventos (Price, 2002, p. 5). Os "primeiros tempos"/"tempos da frente" dos ancestrais estão inseridos num devir histórico plenamente internalizado pelos businenge contemporâneos. Os feitos (principalmente inaugurais, mas não apenas) dos antepassados são eventos que pontuam os movimentos históricos saamaka, extremamente relevantes no presente. Tal história determina quem pertence a qual clã; quem tem o direito de abrir roças ou construir casas onde; quem pode manipular determinados obia ou tocar determinado toque de tambor. "Os que andaram na frente" são uma vanguarda para os que vieram atrás, uma referência constante em suas vidas. A fuga é um tropo da história saamaka, dos mais centrais no entendimento que fazem de si mesmos. Os eventos fundantes dessa 
história foram trilhados como a abertura de uma vereda, o passado dos ancestrais está na frente. A imagem exige do estrangeiro alguma ginástica mental, mas funciona em vários níveis. O futuro, como o que está às nossas costas, não é imediatamente visível, e o passado, como o que está diante de nossos olhos, pode ser visto, ou seja, lembrado, contado.

Ao buscar tal interpretação para a "inversão" espaçotemporal businenge, arrisca-se entrar no delicado campo da filosofia da linguagem. Como dito, não se pretende fazer uma afirmações fortes sobre a ligação entre linguagem, categorias cognitivas temporais e história de uma comunidade linguística. Não se está falando de estrutura gramatical, de categorias temporais mais abstratas como tempo verbal, mas sim de catacreses, tropos e lugares-comuns discursivos de uma retórica sedimentada na história. Em verdade, o argumento é simples: se numa sociedade capitalista é recorrente falar de tempo como algo que pode ser "gasto" (e um clichê pode dizer que "tempo é dinheiro"), parece fazer sentido que numa sociedade fundada por escravos fugitivos - e, particularmente, uma sociedade na qual a memória da resistência e fuga do cativeiro é fundamental para a maneira como narram seu passado - utilize figuras de fuga, de movimentos pela mata, para falar da relação entre o passado, o presente, e o futuro.

Para que tal interpretação se sustente são necessárias duas premissas. A primeira pode ser entendida como uma variante da versão fraca da hipótese Sapir-Whorf, isto é, que “[...] línguas diferentes, em virtudes de suas convenções, facilitam padrões de pensamento diferentes, estratégias retóricas diferentes, argumentos e imagens padronizadas diferentes." (Gell, 2013, p. 126-127). A variante que proponho não isola a língua das historicidades particulares de uma tradição (no sentido a ser elaborado mais a frente). Ou seja, as ideias espaçotemporais eliciadas por certas expressões e práticas saamaka são fundamentadas em seu estilo de vida - sua ética-estética, pode-se dizer - ele mesmo ancorado na geografia histórica acima esboçada.

A segunda premissa é uma consequência da primeira. É preciso rejeitar a suposta universalidade da visão temporal moderna e ocidental, que ampara o conceito de história da historiografia tradicional e a ideia de progresso - aquilo que Benjamin (1987) chama de "tempo vazio 
e homogêneo". Há, pelo mundo, uma multiplicidade de expressões catacrésticas e metafóricas que imbricam espaço e tempo. No vale Yupno na Papua Nova Guiné, por exemplo, associam o passado com "ladeira abaixo" e o futuro com "morro acima", o que seria associado com a topografia local (Núñez et al., 2012). A orientação do sistema de escrita de uma língua parece oferecer conexões entre o passado e o lado direito ou esquerdo, e o futuro com seu oposto (Ouellet et al., 2009 $)^{11}$. Apesar de serem interessantes, as questões que esse tipo de evidência pode levantar acerca do que é tratado neste campo de estudos como "diversidade cognitiva", não busco comparações que visem a compreensão ou a crítica de universais linguísticos. No presente texto, os breves exemplos indo-europeus servem como contrapontos para colocar em relevo as particularidades das ideias businenge do espaçotempo. Contrapontos fundamentais na medida em que se coloca em cheque a suposta a-historicidade do "tempo vazio e homogêneo", linear, que parte de anterior para o posterior. Tal figura do tempo tem também sua fundamentação em um estilo de vida, tendo afinidades, sobretudo, com a ética-estética secular, capitalista e cientificista da modernidade euro-americana.

Por outro lado, no sranan - língua franca no Suriname, mas prioritariamente associada com os creoles (afro-surinameses não descendentes de fugitivos) - ocorrem também "inversões" espaçotemporais similares, ao menos num primeiro nível, aquele mais abstrato: "fesi" é tanto "na frente" quanto "anteriormente" e "baka" é tanto "atrás" quanto "depois". Meu sranan em nível básico não permite que eu avalie se a "inversão" é também utilizada nessa língua em figuras de segundo nível - mais elaboradas, que efetivamente apontam para tradições de historicidade. Tudo indica que não, a julgar pelas expressões apresentadas nos dicionários sranan que tenho disponíveis (Wilner, 2003; Oliveira; Ribeiro, 2011), mas isso sugere mais investigações. Afinal, a atual hipótese filológica é de que todas as línguas crioulas do Suriname possuem uma mesma base, um crioulo das plantações surinamesas, de base lexical inglesa, tendo as línguas businenge se separado a partir das fugas fundacionais de cada grupo, entre 1680 e 1760 (Migge, 2003) ${ }^{12}$. Se as catacreses de segundo nível foram padronizadas antes das fugas, meu argumento perde muito de sua força. 
De todo modo, segue-se com a hipótese de que a "inversão" espaçotemporal em saamakatongo é relacionada com seus "primeiros tempos", que são também os "tempos da frente", das fugas dos ancestrais. Tal hipótese sustenta ainda que línguas, historicidades e tradições estão profundamente imbricadas, ultrapassando limitações de abordagens exclusivamente linguístico-cognitivas. Um ponto fundamental, ainda não mencionado, é o que conectará a presente discussão com a questão da pós-colonialidade: o fato de que as figuras espaciais da quais tratamos até agora não são as únicas que os saamaka utilizam para falar do tempo.

Qualquer língua utiliza figuras espaciais variadas para referirse ao tempo, dependendo, por exemplo, se a referência é um tempo que se move ("o dia está chegando") ou ego que se move ("estamos nos aproximando do Natal"). Nenhuma língua possui um único e coerente modelo catacréstico ou metafórico do tempo (Nuñez; Sweetser, 2006). O mesmo vale para o saamakatongo, que dispõe de diversas maneiras de encarar o tempo, dependendo da pessoa que fala, do evento a que se refere ou do que a situação propor. O tempo pode ser "perdido" ("i ta lasi ten" = "você está perdendo tempo"), ou pode "chegar" ("te dou di juu" = "quando a hora chegar"), apenas para citar algumas variantes. Nessa chave, Bilby (1994, p. 144-145) oferece várias expressões acerca do tempo em aluku, que permitem entendermos como o tempo pode movimentar-se, ser medido e gasto, etc. Ainda assim, as línguas businenge são peculiares na medida em que o pareamento espaçotemporal "invertido" é um padrão para pensar passado e futuro, é a imagem mais recorrente.

Porém, quando os saamaka que conheci falavam sobre questões de desenvolvimento socioeconômico, a ideia do futuro-anterior/passadoposterior não aparecia. Quando a questão passava pela adequação das regras das aldeias ao mundo englobante, pela necessidade de trazer novidades tecnológicas e econômicas ao Alto Suriname, ou por qualquer coisa que fosse entendida como signo de mudanças trazidas por estrangeiros, falavam como quem encara o movimento do mundo como indo em direção a um progresso, que está à frente. Em tais usos, as expressões que utilizam são muito mais familiares: “ $\underline{\mathrm{u} \text { musu luku}}$ 
go a fesi" ("temos que olhar para frente"), "wa musu fika a baka" ("não podemos ficar para trás") e similares. Quem está em movimento aqui não são os falantes, os saamaka, mas os tempos (modernos), na sua própria lógica e direção, quase inexorável, que pode ou não ser acompanhada por quem observa.

Esse outro grupo de figuras de segundo nível vai de encontro a - e também ao encontro de - certa geografia do desenvolvimento do Alto Suriname, território tradicional saamaka. A ideia geral é que, quanto mais distante uma aldeia está da costa (e, portanto, de Paramaribo), quanto mais à libase ("lado de cima", montante), menos desenvolvida ela tende a ser, e quanto mais à bause ("lado de baixo", jusante), mais bens e serviços da cidade chegam, trazendo progresso. Outros fatores, como a presença de uma pista de pouso, de escolas, de igreja, ou a proximidade de uma policlínica também influem no grau de desenvolvimento de uma aldeia específica, mas a ideia geral é que as aldeias ao norte, como as de Bronsweg, atravessadas por estradas, com luz elétrica funcionando 24 horas por dia, tendem a ser mais progressistas, enquanto aquelas mais ao sul, encravadas na floresta, de difícil acesso, como as da região do Gaan Lio, tendem a ser mais tradicionais, guardando uma maior proximidade em seu estilo de vida com o passado ancestral. Certamente, os saamaka sabem muito bem que o eixo jusante-montante não acompanha fielmente um gradiente de maior a menor desenvolvimento socioeconômico. Trata-se mais de um esboço de mapa mental similar à ideia de "interior" enquanto oposto a "capital", no Brasil, por exemplo. Idealmente, o ápice do desenvolvimento neste eixo encontra-se em Paramaribo (onde o Rio Suriname deságua no mar) e, portanto, fora do território tradicional saamaka. O progresso é externalidade, é estrangeiro. A movimentação é tanto no espaço quanto no tempo, e demonstra que, para os saamaka, o tempo "não invertido", no qual o futuro está à frente, tampouco é "vazio": ele é pleno de conotações éticas, estéticas e até mesmo étnicas.

É interessante notar que o trajeto traçado pelos antepassados saamaka na floresta surinamesa teve início nas plantations (na costa ou no Médio Suriname) e seguiu tortuosamente rumo a montante, ao sul, fugindo das forças coloniais. Apenas depois do tratado de paz 
(1763) os saamaka foram gradualmente voltando, fundando aldeias mais a jusante - onde podiam ter mais contato com os intermediários apontados pelo governo para lidar com os businenge "pacificados". Entretanto, aqueles que tinham menos interesse em trocar com os brancos mantiveram suas aldeias ao sul do território tradicional. Isso quer dizer que, na atual geografia do desenvolvimento, quanto mais à montante um saamaka vai, quanto mais segue o caminho dos antigos, idealmente mais distante está dos brancos, do progresso, do desenvolvimento. Isso significa também - e eis o ponto central - que o futuro dos antepassados está do lado oposto do futuro dos brancos, tanto nas falas que abstratamente versam sobre a localização do eixo temporal, quanto nas que territorializam este eixo ao longo do rio onde habitam os saamaka ${ }^{13}$.

\section{Tradição e Desenvolvimento de Frente para Trás}

A oposição entre dois conjuntos de figuras que pareiam espaço e tempo - um que coloca o futuro atrás e o passado na frente, e outro que é o inverso disso - parece aproximar-se, num primeira mirada, da desgastada oposição entre tradição e modernidade. E, de fato, esse par, ou algum semelhante a ele, não deixa de ser relevante no discurso saamaka, como logo veremos. Porém, é preciso marcar que a "inversão" espaçotemporal saamaka não aponta para imagens de uma temporalidade "pré-moderna" cíclica ou estacionária, "tempo frio", "em conserva" ou similares. De fato, os primeiros tempos - que podemos, com os saamaka, entender como marcando sua tradição - não deixam de ser lineares, apesar de serem descritos de maneira oposta à linearidade do tempo do progresso. A contraposição em jogo não necessita trazer com ela outros pares de opostos como selvageria e civilização, pré- e pós-moderno, natureza e cultura.

David Scott - amparado em Talal Asad e Alasdair MacIntyre em diversos pontos de sua obra preocupa-se em pensar criticamente o conceito de tradição. Ele ataca a visão legada pelo iluminismo que coloca a tradição como o oposto da era moderna, como uma orientação vinculada a um antes do tempo em que vivemos, contrária à razão, imune à mudança e intolerante à diversidade. O autor propõe que se 
trate tradição (ou costume) e modernidade (ou progresso) como não necessariamente opostos. A tradição pode ser entendida como um campo discursivo no qual a identidade de uma comunidade é discutida. Ou seja: se a ideia de uma tradição propõe que uma comunidade partilha algo que a distingue de outras - seja um deus, um modo de vida, uma origem traumática, uma história distintiva, uma língua -, ela não deixa de ser marcada por discordâncias, heterogeneidade de perspectivas, conflitos de interpretação (Scott, 2013, p. 2-3). A principal "tarefa" da tradição, de acordo com Scott ([no prelo]), é conectar passados, presentes e futuros, mas para isso ela depende de duas outras tarefas paralelas: legitimar-se perante uma determinada comunidade e instruila um conjunto de virtudes e estilos valorizados (uma ética-estética). Nesse sentido, a tradição é melhor enxergada como um processo ativo. Ela depende de um trabalho contínuo de urdidura das relações, tanto com passados que carregam virtudes a serem produzidas e reproduzidas quanto com futuros almejados. Não se trata meramente de repetir os passos dos antepassados, ou de herdar passivamente uma cultura. É preciso reinventar modos de vida, de olho no presente, no passado, no futuro - a imaginação não é determinada pela tradição, mas é colocada em movimento por ela (Scott, 1999, p. 114-115). ${ }^{14}$

Observei com frequência, no Alto Suriname, dilemas diante dos quais meus interlocutores viam como alternativas opostas o desenvolvimento e a tradição. Dilemas que não são novidades para os businenge: talvez um dos mais dramáticos tenha sido adotar ou não cristianismo, decisão tomada por parcelas saamaka desde o século XVIII ${ }^{15}$. Hoje, esses dilemas atravessam o cotidiano: quando alguém morre afogado no rio, a forma tradicional de despoluí-lo demanda a abstinência de banhar-se, beber, lavar objetos, e mesmo navegar em suas águas por diversos dias, mas isso nem sempre é viável diante das exigências de um trabalho assalariado numa pousada para turistas ou numa policlínica, por exemplo. Quando um homem tem a oportunidade de travar uma relação pessoal com um espírito komati (relacionado aos grandes felinos e ao urubu-rei), capaz de lhe conceder diversos poderes e auxílios, deve pesar se vale a pena seguir seus tabus (tjina), que envolvem, entre outras coisas, não comer determinados tipos de alimentos - para alguém que vai morar na cidade e depende de 
restaurantes, digamos, isso pode ser um problema. A aldeia Daume, considerada uma das mais tradicionais do rio, que possui um poderoso obia que impede a entrada de pessoas brancas em seu solo, quando quer a construção de um sistema de água encanada ou de uma rede de energia elétrica, necessita de modos de contornar as imposições de ancestrais e espíritos. Certos serviços - como aplicar uma massagem em um amigo, ou ajudá-lo a construir o telhado de sua casa - não costumam envolver dinheiro, mas a crescente monetarização da vida nas aldeias muitas vezes exige que passem a exigir pagamento em papel moeda.

Como já deve estar óbvio, é a relação com aqueles que eles chamam de bakaa (brancos, estrangeiros) que insere continuamente elementos externos, compreendidos como fatores de desenvolvimento ou progresso. Pode-se simplificar esses dilemas éticos e estéticos como opondo um modo de fazer as coisas dos antigos - que tinha mais respeito a certos tipos de espíritos, que envolvia uma cooperação interpessoal maior, etc. - e maneiras vistas como novas, importadas - que incluem bens de consumo, dinheiro, medicina alopática e outras benesses. O que está em jogo não é uma simples nostalgia por uma época perdida ou por uma identidade primordial: esses dilemas apontam para modos de vida, de se relacionar com o mundo, e nem sempre partem de uma escolha deliberada acerca de adotar ou não novidades. Os saamaka que conheci não querem ficar "parados no tempo", mas também sabem que isso não seria exatamente uma opção viável, pois se não aprendessem a lidar com tecnologias, religiões, economias, línguas e formas jurídicas estrangeiras, seriam esmagados pela pressão externa.

Certamente, dilemas semelhantes não são exclusividade dos businenge, mas interessa entender os termos a partir dos quais os abordam. Todas essas questões, e muitas outras, geram debates nos quais um modo de fazer as coisas visto como ligado ao ontwikkeling ("desenvolvimento", em neerlandês) e o modo de vida entendido como distintivamente saamaka, que alternadamente chamavam de sua traditie ("tradição", também em neerlandês), kulturu ("cultura" em $\underline{\text { sranan })}$ ou guwenti fasi ("costume" ou, literalmente "modo como estamos acostumados a fazer as coisas", em saamakatongo). A própria escolha de palavras é relevante. A ideia de guwenti fasi é mais propriamente 
descritiva: um costume, um modo de vida, um estilo. Kulturu, termo corrente em todo o Suriname, coloca em relevo a cultura enquanto política das diferenças. Já traditie parece-me uma tradução possível destas duas ideias, capaz de encapsular suas intersecções. Não me lembro de ter ouvido algo que lembrasse o termo "modernidade" sendo usado por um saamaka como oposto a tais ideias, apenas ontwikkeling, o que sugere que uma visão mais processual de progresso do que um período moderno oposto ao tradicional ou ancestral - mais uma vez, não há tempo vazio. É interessante também notar que, para os saamaka com quem conversei, as culturas/tradições/costumes são muitas - cada comunidade tem a sua, e podem, inclusive, ser expressas por essa coleção de expressões, cada uma de uma origem -, enquanto o desenvolvimento é um só, e fundamentalmente bakaa (branco/ europeu/neerlandês).

Uma coisa é provavelmente verdade para toda comunidade fundada por escravos fugitivos, e com certeza o é para os businenge: sua história, em muito de sua dimensão política e econômica, foi construída largamente em contraponto à história do mundo branco, da costa. A escravização os colocou num movimento involuntário e implementou o trabalho forçado; as fugas e guerra contra o poder colonial os colocaram em deslocamento pela selva; os tratados de paz trouxeram uma nova estabilidade e o início de uma reaproximação; as mudanças ao longos dos séculos XIX, XX e XXI, exigem, a cada passo, novas formas de negociação. Isto não quer dizer que a narrativa histórica saamaka dependa da "história mundial" (isto é, da história eurocentrada) ${ }^{16}$. Claro, saber dos ataques franceses ao Suriname em 1712 (Van Lier, 2005, p. 81) ou da crise europeia de crédito de 1772 (Van Lier, 2005, p. 65) não prejudica o acadêmico que pensa o passado businenge, mas nunca foi disso que se tratou, para os próprios businenge. Sua história tem um devir próprio, certamente marcado por irrupções e diálogos com europeus, mas não um mero reflexo disso. Tal devir é profundamente marcado pelos "primeiros tempos".

É preciso, então, lembrar que esses "primeiros tempos" estão na frente. Ao invés de uma tradição anterior e um progresso posterior, o que se revela é uma complexa trama, estendida pelo tempo, de relação entre 
uma internalidade e uma externalidade constantemente reconstruídas, que podem ganhar o nome, hoje, de "tradição" e "desenvolvimento", dois vetores de atração opostos, mas negociáveis. Tal relação certamente não é marcada nem por uma dependência completa, nem por uma resistência surda. A história businenge é, em grande parte, uma história da convivência tensa com o mundo externo, a lógica da fuga convive com a lógica da adaptação constante e, hoje, do progresso. Convivem em mutualismo obrigatório duas histórias, uma interna aos clãs, outra externa, de certa maneira imposta, como convivem dependência e autonomia econômico-social, e como convivem conjuntos de figuras de linguagem que pareiam o espaço e o tempo. Elas podem, muitas vezes, se misturar, se confundir, mas na maioria dos casos parece claro, para os saamaka que conheci, o que é "tradição" e o que é "progresso"; o que são "coisas saamaka" ( branco (bakáa soni).

\section{Na Pós-Colônia, Finalmente}

Achille Mbembe (2001b) critica em sua obra a ideia de tradição tal como foi usada nos estudos africanistas: como signo da diferença irredutível, do princípio da repetição e da imobilidade de valores autóctones. Nesse sentido, em sociedades entendidas como tradicionais, o peso do passado sobredeterminaria o comportamento individual e limitaria as áreas de escolha (Mbembe, 2001a, p. 10) e o progresso, quando introduzido, as desintegraria. Sua sugestão, para fugir da fratura que opõe um antes "tradicional", propriamente africano, mas pré-moderno, a um depois contemporâneo, moderno, mas de origem exógena, é dar atenção ao tempo vivido. Para tal, o autor busca reabilitar

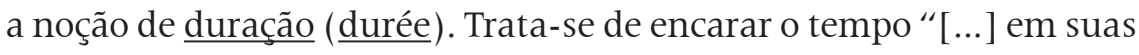
multiplicidades e simultaneidades, suas presenças e ausências, para além das categorias rasas de permanência e mudanças [...]" (Mbembe, 2001 a, p. 8). Como qualquer época (époque), a pós-colonial combina múltiplas temporalidades, é feita de "[...] descontinuidades, reversões, inércias e oscilações que se sobrepõem, interpenetram e envolvem-se umas as outras: um emaranhamento." (Mbembe, 2001a, p. 14, grifo do autor). 
Assim como não é suficiente tratar a tradição como pré-moderna, marcar um antes e um depois da colonização tampouco é suficiente - apesar do "pós" que marca a expressão "pós-colônia". Até porque, num departamento ultramarino como a Guiana Francesa, não se pode dizer que o colonialismo plenamente acabou - e o que dizer dos aluku, pamaka, saamaka e ndyuka, que vivem movendo-se através das fronteiras de uma neocolônia e uma pós-colônia, eventualmente indo até as (ex-)metrópoles? É necessário, então, dar atenção às temporalidades vividas, experienciadas pelas pessoas - as durées nativas, ou o tempo emergente, diria Mbembe (2001a, p. 16). A pós-colônia, como qualquer época, se faz existir de maneira fugidia, num emaranhado. Ainda assim, toda época igualmente apresenta formas particularidades de relação entre subjetividade e temporalidade, algo distintivo e particular, um zeitgeist (Mbembe, 2001a, p. 15), que no caso da pós-colônia, aponta para "[...] uma experiência de um ofuscante pluralismo temporal [...]", atravessada pelas incompletudes deixadas pela dominação colonial, mas não apenas por elas (Reinhardt, 1998, p. 361). A pós-colônia é um espaço de proliferação, no qual eventos são vividos como se estivessem uns sobre os outros e que, mesmo advindo da violência, não se resume ao caos (Mbembe, 2001a, p. 242).

Assim, compreende-se que os saamaka, os businenge e o Suriname estão plenamente inseridos numa época pós-colonial. Porém, uma dificuldade de usar Mbembe no contexto etnográfico businenge reside no fato de que o autor opera sempre em larguíssima escala, falando da África subsaariana como um todo, em sua conexão com a economia e a política internacional. É provável que uma leitura cuidadosa de sua leitura da pós-colonialidade africana pudesse fornecer elementos para pensar o Suriname atual, em termos da fundação de sua soberania e do imaginário que a sustenta, bem como das transformações nesse fundamento atravessadas desde o fim da guerra fria e a reorganização de novas formas de legitimidade. Seria proveitosa uma análise que analisasse a tentativa de certos líderes nacionais (da situação e da oposição) de desenharem-se como o autocrata descrito por Mbembe (2001a, p. 142-172). Porém, isso foge em muito do escopo deste artigo.

De todo modo, o aspecto temporal da pós-colônia descrita por Mbembe, em suas múltiplas durações, ressoa de forma explícita nas 
maneiras que os saamaka falam espacialmente do(s) tempo(s) em que se encontram. Se o colonialismo inaugurou um novo terreno no qual certas formas de acomodação e resistência são possíveis (Scott, 1999, p. 17), para os businenge, inaugurou muito mais. A fuga de seus ancestrais instaurou o grande eixo temporal histórico "de frente para trás" que os saamaka seguem para construir sua sociedade, um eixo marcado no espaço, um caminho na mata. Por outro lado, sempre se contrapondo a uma sociedade colonial (hoje um estado nacional), foram obrigados a lidar sempre com um tempo externo e oposto ao seu, "de trás pra frente", que tenta capturá-los. O extremo cuidado com que lidam com o equilíbrio entre tradição e desenvolvimento é marcado justamente pela compreensão de que a contraposição é incontornável, ainda que a aproximação seja sempre tensa, perigosa - não apenas dada a violência dos choques com o estado e com o mercado, mas também pelo perigo que pode representar ir contra vontades de ancestrais e divindades. Este devir histórico de dois eixos é uma forma de lutar contra "o Um da história, pela Relação das histórias", como coloca Glissant (2001, p. 151). Ou, nas palavras de Mbembe:

Esta "saída"17 não é pura e simplesmente "desvinculação [de-linking] ou "desengajamento [disengagement], ou mesmo "marginalização" no sentido estrito. Enquanto anverso do "tempo mundial" no qual se emaranham uma multiplicidade de fluxos, ela é um aspecto de um complexo movimento desdobrando-se em escala global. Neste entrelaçamento de temporalidades, diversos processos coexistem: há processos que tendem a fazer as pessoas verem as coisas cada vez mais de maneiras similares e, ao mesmo tempo, processos produzindo diferenças e diversidades. Em suma, dinâmicas contraditórias estão em jogo, feitas de lapsos, disjunções, e diferentes velocidades. É demasiado fácil reduzir tais dinâmicas ao simples antagonismo entre forças internas e externas. (Mbembe, 2001a, p. 73, grifos nossos)

Dinâmicas contraditórias, no anverso do "tempo mundial", ultrapassam um antagonismo entre externalidade e internalidade, ainda que não deixem de se basear neles. É nesse sentido que as traditie, kulturu ou guwenti fasi - já em si múltiplas pelos diferentes 
signos que carregam - operam como contraponto e contradiscurso a um projeto de desenvolvimento mundial que tende a passar por cima da diversidade (falando de modo genérico) e dos saamaka, de seu rio, seu solo e sua floresta (para ser mais específico). Para dar um exemplo concreto, negando a possibilidade de direitos específicos para populações tradicionais a partir do argumento de que a cidadania em um estado moderno não deve fazer distinções entre as diferentes populações que o compõem. Os saamaka hoje estão em uma disputa político-legal com o estado surinamês para garantir a propriedade coletiva de seu território tradicional, algo repelido pela elite surinamesa sob argumentos "modernizadores"18.

Scott (2013) lembra que a tradição - ao menos nos casos dos povos colonizados - passa por poder e oposição. As culturas, neste sentido, propõem-se como opostas a uma homogeneização cujo vetor vem do exterior e podem ser, portanto, entendidas como contraculturas. Longe de uma visão essencializante da tradição, o autor nos convida a buscar entender "[...] a complexidade e a natureza multiforme dos projetos políticos nos quais seu uso é frequente" (Cunha, 2002, p. 152). As críticas à oposição simplista entre tradição e modernidade, é claro, não começam nem terminarão com Scott ou com a teoria pós-colonial. Mas é interessante notar que o autor jamaicano, assim como o martinicano Édouard Glissant, busca revitalizar, sob um ponto de vista menos dicotômico, menos simplista e eurocêntrico, ideias como as de tradição e mesmo a de "raízes". Glissant (2005) substitui a oposição elaborada por Deleuze e Guattari (1995) entre rizoma e raiz, por outra, bastante similar, entre raiz-única e raiz-rizoma - a primeira arborescente, territorializante, atávica; a segunda vivaz, desterritorializante, compósita. Com a ligeira modificação conceitual, o martinicano insiste em não deixar de lado as raízes - estejam nas Antilhas ou na África, mais provavelmente em diversos lugares enquanto aquilo que ancora sua posição, seu lugar. Ao constituir uma relação, ao abrir-se para a exterioridade, com fins de não se perder no caos-mundo ou nos lugares-comuns, elabora Glissant (2005, p. 25), é fundamental manter o lugar de onde se emite a fala. A questão é "[...] como ser si mesmo sem fechar-se ao outro, e como abrir-se ao 
outro sem perder-se a si mesmo [...]" (Glissant, 2005, p. 28), buscando um "[...] desvio que não é fuga nem renúncia, mas a arte nova do desatamento do mundo" (Glissant, 2005, p. 84). A complexidade das ideias de tradição trazidas por esses pensadores que pensam e vivem a pós-colônia, a negritude e a caribeanidade, trazem à mente uma afirmação de Bastide:

[...] a imagem do homem marginal, dividido entre duas culturas que se batem dentro dele, talvez valha para o intelectual de cor; seguramente, não vale para o homem do povo. Este vive sem problema, em muitos mundos que não se defrontam, pois não ocupam os mesmos setores da vida, técnico, econômico, político e religioso. (Bastide, 1974, p. 179)

Em outras palavras, o problema da dupla consciência, conceitualizado por Du Bois (1999) e que tantas páginas de discussão rendeu nos campos dos estudos afro-americanos (Gilroy, 2001), seria um problema da burguesia intelectualizada negra, mas não da maioria da gente preta. Pensando nos saamaka com quem convivi - pouquíssimos deles intelectuais no sentido estrito - vejo-me obrigado a discordar de Bastide. O problema da conciliação entre culturas, ou entre tradição e desenvolvimento, ou entre internalidade e externalidade, afeta, em muito, o pensar e o agir no Alto Suriname, onde os "setores da vida" não estão apartados: barcos a remos são utilizados ao lado daqueles com motor de popa, o dinheiro convive de maneira tensa com esferas de trocas cerimoniais (Pires [no prelo] a), as decisões acerca de cargos tradicionais se mesclam com questões de partidos concorrendo ao parlamento nacional, o cristianismo se comunica, não sem ruído, com divindades e obia.

Glissant (2005, p. 109) diz que todo povo necessita de meios para refletir sobre sua presença no "não-sistema de relações do Todo-omundo", para evitar ser colocado na posição de "um povo oprimido, um povo mantido em estado de incapacidade". Entende-se que o delicado equilíbrio entre tradição e desenvolvimento que buscam os saamaka é fruto de uma reflexão e de uma práxis para fugir desse estado de opressão. E a multiplicidade das figuras temporais que utilizam é uma 
materialização, no discurso, da duplicidade que vivem e a partir da qual pensam.

Viver a pós-colonialidade não se limita a uma relação entre nações ex-colonizadas e ex-metropolitanas. Os efeitos dessa época não acabam nas políticas migratórias, nas relações com a pluralidade dos dois lados do Atlântico, e nem mesmo com a economia transnacional que penetra naquilo que um dia foi chamado de periferia. A pós-colônia, como nos ensinam Mbembe, Scott, Glissant e outros, é também um espaço-tempo de produção de subjetividades e modos de vida (isto é, de produção de si mesmo e de outrem). Os businenge do Suriname e da Guiana Francesa vivem numa época que sucede o colonialismo, num espaço formado pelos efeitos das governamentalidades desenvolvidas e aplicadas pelas potências europeias na região onde vivem, na margem entre o Caribe e a América do Sul. Um tempo-espaço de temporalidades múltiplas e emaranhadas, de vetores e mesmo desejos contraditórios. Talvez por isso, os businenge encarem suas tradições a partir da possibilidade de dissenção ${ }^{19}$.

Ouso dizer que é provável que os businenge tenham estado entre os primeiros a viverem uma época semelhante ao que hoje chamamos de pós-colônia. O poder colonial não buscou apenas efeitos extrativos, mas também efeitos governamentais sob a conduta colonial. Isto incluiu desenhar instituições a partir das quais os "nativos" poderiam se autogovernar - sob os olhos atentos dos colonizadores, claro (Scott, 1999, p. 51). Nesse sentido, é possível abordar os tratados de paz com os businenge, bem como com os maroons jamaicanos, como ensaios de governamentalidade colonial. Estão entre os primeiros movimentos anteriores mesmo à revolução haitiana - de uma transigência oficial dos colonizadores em direção ao autogoverno de populações negras no Novo Mundo. O que não quer dizer que, ao mesmo tempo, não sejam ícones da vitória daqueles ex-escravos que lutaram para consegui-los. Os tratados de paz não apenas foram os primeiros capítulos da descolonização no Caribe, foram também o início de uma pós-colonialidade que não necessitou de esperar o colonialismo acabar para se instaurar. 


\section{Notas}

1 Trechos deste artigo, sobretudo das seções 3 e 4, foram adaptados da conclusão de minha tese de doutorado, na qual conecto imagens espaçotemporais saamaka à temporalidade de seus rituais funerários e, de maneira mais ampla, aos tempos dos mortos, que a partir de diversos modi operandi - espíritos vingativos, padrinhos espirituais, fantasmas, antepassados, figuras históricas - são centrais para entender o tempo e o espaço na cosmologia saamaka (Pires 2015, p. 381-432). Agradeço, pela ajuda na elaboração de tais ideias na tese, a Olívia M. G. da Cunha e Márcio Goldman; e pela leitura atenta das primeiras versões deste artigo, além do convite para contribuir ao presente dossiê, a Letícia Cesarino e Bruno Reinhardt.

2 Dentre os termos utilizados para descrever os vários tipos de comunidades estabelecidas por escravos fugitivos - mocambo, palenque, cimarrones, etc. - "quilombo" estabeleceu-se no Brasil e, aqui, tende a ser usado de maneria genérica para falar de grupos por toda a América. Eu, porém, opto por marcar as diferenças existentes entre essas comunidades, utilizando maroon comunidades jamaicanas, neg'mawon para o Haiti e assim por diante. Para o contexto das Guianas, foco de meu trabalho, utilizo businenge - termo utilizado pelos próprios, e que significa literalmente "negros do mato". Os businenge das Guianas são divididos em seis grupos - Matawai, Saamaka, Ndyuka, Pamaka, Aluku e Kwinti - todos relativamente similares entre si, mas politicamente e territorialmente distintos. Cada um têm sua estrutura autônoma de cargos políticos e seu território tradicional no interior selvoso do Suriname da Guiana Francesa. Relevante para o tema a ser discutido, cada grupo businenge possui uma língua própria, ainda que sejam agrupadas por alguns linguistas entre ocidentais - matawai e saamaka - e orientais - ndyuka, pamaka e aluku -, estando a língua kwinti entre elas. Todas são relacionadas com a língua crioula falada no restante do Suriname, o sranan. Esses grupos em conjunto formam hoje cerca de $20 \%$ da população de aproximadamente 600.000 habitantes do Suriname, e 25\% da população de aproximadamente 250.000 habitantes da Guiana Francesa. Além de seus territórios tradicionais nas florestas ao sul desses países, possuem forte presença urbana na região. Businenge são considerados como nitidamente distintos dos afro-surinameses e afroguianenenses não descendentes de escravos fugitivos, aos quais me referirei, seguindo a terminologia local, como creoles. Tanto o Suriname quanto a Guiana Francesa ainda têm populações numerosas de pessoas de ascendências asiática (indiana, javanesa, chinesa, hmong). Para mais informações acerca do Suriname, dos businenge e para detalhes acerca de meu trabalho de campo, ver Pires, 2015, p. 3-31.

3 Sobre os maroons da Jamaica, ver Bilby, 2006.

4 Certamente, um questionamento similar poderia ser feito em relação aos ameríndios, que quase sempre aparecem nas historias do Caribe como prefácio ou parágrafo introdutório: para a historiografia canônica, o Caribe "propriamente dito" começa com a aniquilação dos povos autóctones. Cabe também marcar, já que passamos rapidamente pelo Haiti, que esse país e sua história também foram tratados como “excepcionais" pela teoria social caribeanista, ponto debatido por Trouillot (1990).

5 Dentre os autores no debate neerlandófono contemporâneo, Oostindie (2010, p. 17) deixa claro que limita seu entendimento do pós-colonial ao "sentido temporal e demográfico", enquanto Wekker (2016, p. 175, n. 1) vincula-se à tradição crítica acadêmica que chama de decolonial, para distinguir do uso mais supostamente neutro da ideia de pós-colônia. 
6 Todas as traduções de textos que não estão em português na bibliografia são de minha autoria. Para a introdução de Mbembe (200la) existe uma versão em português (Mbembe, 2015).

7 Esse problema etnográfico poderia proveitosamente ser tratado através de outras abordagens teóricas. Por exemplo, usando o conceito bakhtiniano de cronótopos, enquanto formas de modulação ontológica do tempo-espaço - trabalhados, dentre outros, por Wirtz (2016) e o artigo de Reinhardt publicado neste volume (Reinhardt, [no prelo]). Porém, o experimento que proponho me leva a evitar abrir tal porta.

8 As aspas protegem-me de enunciar a fórmula "futuro: posterior: passado: anterior" como "norma" para qual as "inversões" businenge, fijiana, aymara e possivelmente outras seriam desvios aberrantes... Ainda que, como dito, tal fórmula seja extremamente recorrente em línguas por todo o mundo.

9 Cabe notar que baka e fesi possuem também um sentido corporal (respectivamente "costas" e "face"). Tal dimensão corporificada reforça o apontamento de que a genealogia (ou seja, o parentesco, a composição de pessoas) também é fundamental para compreender o espaço-tempo saamaka - as pessoas são em parte constituídas a partir de uma relação com o território de suas linhagens, marcado por movimentos e ações de antepassados.

${ }^{10}$ Para não deixar totalmente de lado a África, tropo que faz par com a escravidão no discurso acadêmico e ativista sobre as populações afro-americanas ( Scott, [no prelo]), é importante afirmar que o período africano, pré-escravidão, é relevante para os saamaka, mas é distante e relativamente pouco elaborado em suas narrativas históricas atuais. Isso faz com que a África acabe ganhando feições do que chamamos de tempo mítico: o passar dos anos já não altera a relação das pessoas que vivem hoje com os ancestrais mais remotos, do outro lado do Atlântico. Ver a discussão de Bilby (1994, p. 158) acerca do "teto" temporal nas histórias de povos ascendência africana no Novo Mundo.

${ }^{11}$ Em estudos deste tipo, gestos também são levados em conta. Infelizmente, não coletei dados acerca do gestual saamaka para indicar o movimento do/no tempo.

12 As línguas saamaka e matawai - as primeiras a se separarem - sofreram uma crucial influência do dju tongo ("língua judia"), um crioulo de base lexical portuguesa falada por escravos de judeus lusófonos que se instalaram na colônia por volta de 1665 (Aboh; Smith; Veenstra, 2013). De acordo com Norval Smith (apud Migge, 2003 , p. 56), o vocabulário saamaka é 50\% composto de palavras derivadas do inglês e $34 \%$ de palavras derivadas do português. Note que tanto no saamaka quanto no sranan, os termos centrais em minha discussão, "baka" e "fesi", são idênticos, derivados de palavras inglesas, "back" e "face", respectivamente.

${ }^{13}$ Um outro par de opostos saamaka também ganha mais sentido quando falamos do futuro como estando atrás. Falando do espaço da aldeia, é comum marcar uma oposição concêntrica entre ganda, o centro humano, onde fica aldeia e as pessoas moram, e bakase (lit. "lado de trás"), o que inclui a floresta, mas também as roças que são cortadas nela. A expansão territorial de uma aldeia saamaka ao longo do tempo dá-se em direção à parte de trás: devido ao aumento populacional, a aldeia vai ganhando o espaço da floresta à medida que novas casas vão sendo construídas e uma maior quantidade de roças vai sendo cortada. Bakase vai virando ganda, a floresta vai sendo domesticada, tornada morada de seres humanos. Estabelecer uma aldeia - construí-la - é "cortar uma aldeia" ( koti wan konde), em referência à derrubada do mato necessária para fazer de uma área que era bakase em ganda. O futuro comporta um movimento de expansão em direção à "parte de trás". Da 
mesma forma, faz sentido que o cemitério seja considerado parte de bakase, pois, além de ficar na mata, o futuro de todos é a morte e, portanto, a "parte de trás", fora da aldeia e do domínio humano (Pires, 2015, p. 227-230).

14 A crítica que Scott tece a autores que etnografaram os saamaka - Melville Herskovits e Richard Price - vai na direção de enfatizar, através de seu conceito de tradição, a dimensão ética-estética frente a um "verificacionismo" que busca autorizar através da ciência antropológica afirmações acerca da rememoração de um passado africano e/ou escravo em seu presente (Scott, [no prelo]). Ver nota 10 (supra).

15 Tendo baseado meu trabalho de campo em uma aldeia cristã (vinculada à Igreja Moraviana do Suriname), discuto o assunto longamente em minha tese (Pires, 2015 , p. 277ss.) Cabe frisar que dentre os saamaka hoje, aproximadamente $20 \%$ são cristãos e a enorme maioria desse quinto conjuga o cristianismo com seu complexo de matriz africana, não nomeado, que inclui fórmulas e objetos mágicos (obia), diversas formas de divindades e espíritos (gadu) e variadas formas de relações com os ancestrais.

16 Como ocorre em outros casos, qual o martinicano, pace Glissant (2010, p. 148-150).

17 Aqui o autor fala mais especificamente sobre um movimento econômico de direcionamento para os canais subterrâneos, mas a afirmação pode ser lida num sentido mais amplo.

18 Sobre a disputa pelo reconhecimento do território tradicional saamaka, ver Price (2011).

19 Sobre a dissenção e o consenso internos às aldeias saamaka, sua forma de estabelecer as "regras" a partir de seus costumes e da externalidade.

\section{Referências}

ABOH, Enoch O.; SMITH, Norval S. H.; VEENSTRA, Tonjes. Saramacan. In: MICHAELIS, Susanne Maria et al. (Ed.). The Survey of Pidgin and

Creole Languages: English-based and Dutch-based Languages. Oxford: Oxford University Press, 2013. v. I. p. 27-38.

BALKENHOL, Markus. Silence and the Politics of Compassion: Commemorating Slavery in the Netherlands. Social Anthropology, Cambridge, v. 24, n. 3, p. 278-293, 2016.

BASTIDE, Roger. As Américas Negras. São Paulo: Difusão Europeia do Livro, [1967] 1974.

BENJAMIN, Walter. Sobre o Conceito de História. In: BENJAMIN, Walter. Magia e Técnica, Arte e Política: ensaios sobre Literatura e História da Cultura. São Paulo: Brasiliense, [1940] 1987. p. 222-232.

BILBY, Kenneth. The Remaking of the Aluku: Culture, Politics and Maroon Ethnicity on French South America. Baltimore: Ph.D. Dissertation, Johns Hopkins University, 1990.

BILBY, Kenneth. Time and History among a Maroon People: The Aluku. In: ADJAYE, Joseph K. (Ed.). Time in the Black Experience. Westport: Greenwood, 1994. p. 141-160. 
BILBY, Kenneth. True Born Maroons. Kingston: Ian Randle, 2006.

BOEHMER, Elleke; MUL, Sarah de. Towards a Neerlandophone Postcolonial Studies. Journal of Diversity and Gender Studies, Leuven, v. 1, n. 1, p. 61-72, 2014.

BOSMA, Ulbe. Why is There no Post-colonial Debate in the Netherlands? In: BOSMA, Ulbe (Ed.). Post-colonial Immigrants and Identity Formations in the Netherlands. Amsterdam: Amsterdam University Press, 2012. p. 193-212.

CARVALHO, José Jorge de. O Quilombo do Rio das Rãs: Histórias, Tradições, Lutas. Salvador: EDUFBA, 1996.

CUNHA, Olivia M. Gomes da. (Re)creating Spaces and Times: the Cottica Ndyuka in Moengo. In: COLLINS, John Collins; McGRANAHAN, Carole (Ed.). Ethnographies of U.S. Empire. Durham: Duke University Press, [no prelo].

CUNHA, Olívia Maria Gomes da. Reflexões sobre Biopoder e Póscolonialismo: Relendo Fanon e Foucault. Mana, Rio de Janeiro, v. 8, n. 1, p. 149-163, 2002.

DE KOM, Anton. Nosotros, Esclavos de Surinam. La Habana: Casa de Las Americas, [1934] 1981.

DELEUZE, Gilles; GUATTARI, Félix. Introdução: Rizoma. In: DELEUZE, Gilles; GUATTARI, Félix. Mil Platôs: Capitalismo e Esquizofrenia, São Paulo: 34, [1976] 1995. v. 1. p. 11-37.

DEOGRATIAS, Benedicta; SINGLETON, Kyera; WOTJALEWICZ, Casey. Race in the Netherlands: The Place of the Surinamese in Contemporary Dutch Society, 2011. Disponível em: < http://www.humanityinaction.org/ knowledgebase/372-race-in-the-netherlands-the-place-of-the-surinamesein-contemporary-dutch-society>. Acesso em: 15 jun. 2017.

DU BOIS, W. E. B. As Almas da Gente Negra. Rio de Janeiro: Lacerda, [1903] 1999.

ESSED, Philomena. Understanding Everyday Racism: An Interdisciplinary Theory. Newbury Park: Sage, 1991.

GELL, Alfred. A Antropologia do Tempo: construções culturais de mapas e imagens temporais. Petrópolis: Vozes, [1992] 2013.

GILROY, Paul. O Atlântico Negro: modernidade e dupla consciência. São Paulo: 34, [1993] 2001.

GLISSANT, Édouard. El Discurso Antillano. La Habana: Casa de las Américas, [1981] 2010. 
GLISSANT, Édouard. Introdução a uma Poética da Diversidade. Juiz de Fora: UFJF, [1995] 2005.

GOURY, Laurence; MIGGE, Bettina. Grammaire du Nengee:

Introduction aux Langues Aluku, Ndyuka et Pamaka. Paris: IRD Éditions, 2003.

HERSKOVITS, Melville J. Preliminary Report of an Ethnological Expedition to Suriname, 1928. New West Indian Guide, Leiden, v. 10, n. 1, p. 385$390,1929$.

HERSKOVITS, Melville J. The Myth of the Negro Past. New York: Beacon, 1941.

JAMES, C. L. R. Os Jacobinos Negros: Toussaint de L'Ouverture e a Revolução de São Domingos. São Paulo: Boitempo, [1938] 2000.

LACLAU, Ernesto. L'Articulation du Sens et les Limites de la Métaphore. Archives de Philosophie, Paris, v. 70, n. 4, p. 299-624, 2007.

MBEMBE, Achille. As Formas Africanas de Auto-Inscrição. Estudos AfroAsiáticos, Rio de Janeiro, v. 23, n. 1, p. 171-209, 2001 b.

MBEMBE, Achille. O Tempo que se Move. Cadernos de Campo, São Paulo, v. 24, p. 369-397, [2000] 2015.

MBEMBE, Achille. On the Postcolony. Berkeley: University of California Press, [2000] 2001a.

MIGGE, Bettina. Creole Formation as Language Contact: The Case of the Suriname Creoles. Amsterdam: John Benjamins, 2003.

NÚÑEZ, Rafael et al. Contours of time: Topographic Construals of Past, Present and Future in the Yupno Valley of Papua New Guinea. Cognition, Amsterdam, v. 124, n. 1, p. 25-35, 2012.

NÚNEEZ, Rafael; SWEETSER, Eve. With the Future Behind Them: Convergent Evidence from Aymara Language and Gesture in the Crosslinguistic Comparison of Spatial Construals of Time. Cognitive Science, Bloomington, v. 30, p. 1-49, 2006.

OLIVEIRA, Rafael da Silva; RIBEIRO, José Paulo. Wortubuku Sranantongo para Brasileiros. Brasília: Fundação Alexandre Gusmão, 2011.

OOSTINDIE, Gert. Postcolonial Netherlands: Sixty-five Years of Forgetting, Commemorating, Silencing. Amsterdam: Amsterdam University Press, 2010.

OOSTINDIE, Gert; KLINKERS, Inge. Introduction. In: OOSTINDIE, Gert; KLINKERS, Inge. Decolonizing the Caribbean: Dutch Policies in a Comparative Perspective. Amsterdam: Amsterdam University Press, 2003. p. 9-16. 
OUELLET, Marc et al. Multimodal Influences of Ortographic Directionality on the "Time is Space" Conceptual Metaphor. In: TAATGEN, Niels; RIJN, Hedderik van (Ed.). Proceedings of the 31th Annual Conference of the Cognitive Science Society. Amsterdam: Cognitive Science Society, 2009. p. 1.840-1.845.

PAKOSIE, André R. Maroon Leadership and the Surinamese State (17601990). Journal of Legal Pluralism and Unofficial Law, [S.l.], v. 37-38, p. 263-277, 1996.

PIRES, Rogério Brittes W. “The Way We're Used to": Funerary Rules in Upper Suriname. In: CUNHA, Olívia Maria Gomes da (Ed.). Maroon

Cosmopolitics: personhoood, creativity and incorporation. Leiden: Brill, [no prelo].

PIRES, Rogério Brittes W. A Mása Gádu Kondë: Morte, Espíritos e Rituais Funerários em uma Aldeia Saamaka Cristã. Rio de Janeiro: Tese de Doutorado, PPGAS/MN/UFRJ, 2015.

PIRES, Rogério Brittes W. Dinheiro, Tecidos, Rum e a Estética do Eclipsamento em Saamaka. Mana, Rio de Janeiro, [no prelo].

PRICE, Richard. First-Time: The Historical Vision of an African American People. Chicago: The University of Chicago Press, [1983] 2002.

PRICE, Richard. Rainforest Warriors: Human Rights on Trial. Philadelphia: University of Pennsylvania Press, 2011.

PRICE, Richard. The Maroon Population Explosion: Suriname and Guyane. New West Indian Guide, Leiden, n. 87, p. 323-327, 2013.

RAMDAS, Anil. Madame Bovary. Callaloo, College Station, v. 21, n. 3, p. 523-538, [1992] 1998.

REINHARDT, Bruno. Poder, História e Coetaneidade: os lugares do colonialismo na antropologia sobre a África. Revista de Antropologia, São Paulo, v. 57, n. 2, p. 329-275, 2014.

REINHARDT, Bruno. Temporalidade, Ética e Contingência na Pós-Colônia Africana: Esperando por Deus em Gana. Revista Ilha, Florianópolis, [no prelo].

SCOTT, David. Aquele Evento, Esta Memória: Notas sobre a Antropologia das Diásporas Africanas no Novo Mundo. Revista Ilha, Florianópolis, [1991] [no prelo].

SCOTT, David. On the Very Idea of a Black Radical Tradition. Small Axe, New York, v. 40, p. 1-6, 2013.

SCOTT, David. Refashioning Futures: Criticism after Postcoloniality.

Princeton: Princeton University Press, 1999. 
TOREN, Christina. A Matéria da Imaginação: o que podemos aprender com as ideias das crianças fijianas sobre suas vidas como adultos. Horizontes Antropológicos, Porto Alegre, v. 16, n. 34, p. 19-48, 2010.

TROUILLOT, Michel-Rolph. The Odd and the Ordinary: Haiti, the Caribbean, and the World. Cimarron, [S.l.], n. 3, p. 3-12, 1990.

VAN LIER, R. A. J. Sociedade de Fronteira: uma análise social da história do Suriname. Brasília: Funag/IPRI, [1949] 2005.

WEKKER, Gloria. White Innocence: Paradoxes of Colonialism and Race. Durham: Duke University Press, 2016.

WILNER, John (Ed.). Wortubuku ini Sranan Tongo (Sranan Tongo English Dictionary). Paramaribo: Summer Institute of Linguistics, 2003.

WIRTZ, Kristina. The Living, the Dead and the Immanent: Dialogue Across Chronotopes. Hau: Journal of Ethnographic Theory, London, v. 6, n. 1, p. 343-369.

Recebido em 03/08/2017

Aceito em 16/09/2017 